Investigaciones Fenomenológicas, vol. Monográfico 4/I (2013): Razón y vida, 197-218. e-ISSN: $1885-1088$

\title{
The CRISIS Of EUROPEAN SOCIAL SCIENCES: The Case of Money
}

\section{LA CRISIS DE LAS CIENCIAS SOCIALES EUROPEAS: EL CASO DEL DINERO}

\author{
Joan González Guardiola \\ Grup d'Estudis Fenomenològics / \\ Societat Catalana de Filosofía, España \\ phaenom11@hotmail.com
}

\begin{abstract}
Our aim in this article is to put into practice, in the field of social sciences, the principles that Husserl displayed in his book from 1936, "The crisis of European sciences and transcendental phenomenology". In that seminal work, Husserl reflected on the mathematization of nature and produced an historical meditation on the essence of geometry. Here we will try to extend the reach of Husserlian postulates in order to deal with economics and, more specifically, with the theory of money. We think that, in certain social sciences, and in particular in those with a clear mathematical penchant like economics, the use of formalization often helps to cover an uncritical use of phenomenologically ungrounded idealizations. This fact ultimately results in a massive concealment of the true sense of some of its principal phenomena -namely, money. It is worth mentioning that this concern does not have its roots only in phenomenology, for even academic monetary theory openly acknowledges that we lack an understanding of the meaning of money which could help us clarify and prevent financial crisis and economic collapses. Crisis, in short, are not the result of a deep understanding of the concept of money; on the contrary, they highlight the fact that we don't really know what money is. Thus, our goal here is to illustrate the possibilities offered by the phenomenological method in its application to the question of money. It is in this sense that the research taking place here can be understood as a "phenomenological critique of monetary theory".
\end{abstract}

Key Words: Phenomenology of Money, Monetary Theory, Medium of Exchange, Crisis of European Sciences.
Resumen: En el presente artículo se pretende llevar a cabo una aplicación de los principios que Husserl lleva a cabo en su obra de 1936, "La crisis de las ciencias europeas y la fenomenología transcendental", a las ciencias sociales; concretamente, al concepto de dinero. En su obra de 1936, Husserl puso el énfasis en la matematización de la naturaleza, centrándose sobre todo en la meditación histórica sobre la geometría. Pero en el caso de algunas ciencias sociales, como la economía, la utilización libre de construcciones idealizadoras fenomenológicamente infundadas, como en el caso del dinero, está teniendo como resultado un enorme encubrimiento de sentido del fenómeno monetario. Esto no es vivido tan solo desde la fenomenología: desde la propia teoría monetaria se reconoce que estamos faltos de una comprensión del sentido del dinero que nos ayude a clarificar y prevenir de manera suficiente las crisis financieras. Estas crisis no son fruto de que hayamos comprendido demasiado bien el concepto de dinero, sino de que todavía estamos faltos de una comprensión profunda del sentido del dinero. Aquí pretendemos ilustrar las posibilidades que el método fenomenológico ofrece, aplicado al caso del dinero. En este sentido, pueden considerarse las investigaciones que tienen lugar aquí como "crítica fenomenológica de la teoría monetaria".

Palabras clave: Fenomenología del dinero, teoría monetaria, medio de cambio, crisis de las ciencias europeas. 


\section{Presentation of the problem}

Our aim in this paper is to apply some of the most important elements of the phenomenological critique to the scientific notion of "objectivity", such as it can be found in "The Crisis of the European Sciences and Transcendental Phenomenology" to the field of monetary theory. It is known that Husserl devoted himself specially to the analysis of the constitution of modern physics, as a basis of the natural sciences ${ }^{1}$, and to the constitution of psychology as a natural science, due to its peculiar relation to transcendental phenomenology ${ }^{2}$, leaving aside the foundations of many other sciences that did not require a special treatment in a piece of work of a general character ${ }^{3}$. On the other hand, the references in the work of Husserl to economy as science are non-existent ${ }^{4}$. In the context of this paper, our aim is to present the elements of a phenomenological critique to money using the methodological concept of "model".

It is a commonplace to virtually all economic textbooks to understand the definition of money within what might be called a "functional definition". There is an expression that has made fortune in this respect: money is what money does $^{5}$. Accordingly, money is "anything" capable of carrying out the well-known four following functions:

- UNITY OF ACCOUNT: Money provides a measure or homogeneous pattern in which to express debts, prices and the general power of acquisition in establishing equivalences between cash and property.

- Medium of exchange: Money can be exchanged for other goods. In this sense, money is a commodity that is constituted as a medium of exchange commonly accepted in indirect exchanges ${ }^{6}$.

\footnotetext{
${ }^{1}$ Hua VI, § [9], etc.

${ }^{2}$ Hua VI, § [57], [58].

3 The theory of science of Ideen III, according to which regional ontologies depend on the theory of apprehensions seems to exclude a differentiated phenomenological foundation for the social sciences; see Hua V, § [4].

${ }^{4}$ Some attempts to advance in the direction of integrating the foundations of the theory of the life-world and the foundations of economy are offered in a dispersed fashion, without a systematic impulse, for example, in Stikkers (1985).

${ }^{5}$ Hicks, 1967, p. 1.

${ }^{6}$ As "direct exchange" we mean the primary model of barter exchange, "piece by piece" constituted upon the spontaneous coincidence of interests in relation to the goods that the agents need and the goods they want to get rid of: the goods I possess and do not need coincide with the ones the other possesses and does not need. The exchange is indirect when buying goods, not based on a coincidence of direct interests, but to have access in a future exchange to other goods that are not phenomenologically present. The indirect exchange is an exchange that involves mediation between the
} 
- Means of payment: Money is used to settle liabilities or debts to individuals or institutions. For example, we use money to pay taxes.

- StORe of WeAlth: Money allows you to maintain your purchasing power from present to future. As a store of wealth it is deficient against future price increases, because this purchasing power may decrease, but in principle it serves to accumulate purchasing power in future situations ${ }^{7}$.

In a first analysis of this traditional functional definition we will readily find the following problematic aspects:

1. Most formulations talk about "anything". It does not matter whether it is this or that, but there has to be "something" 8 . At first sight, this might be without interest, but later it will appear to have important ramifications.

2. This "thing" has historically been interpreted most times as something which belongs to the region "physical thing" (a commodity).

3. In the history of economic thought, the function that has been traditionally privileged as primary function is the medium of exchange function.

4. This predominance of the medium of exchange function has been accompanied by a genetic conception of all other forms of money (fiat money, electronic money, etc.) from this "money-thing".

We can call the set of conditions (2)-(4) as the foundation of what in contemporary monetary theory has been called "orthodox analysis" ${ }^{9}$, a scholarly historical construct that some make it go back to the first description about the origins of money in Aristotle ${ }^{10}$, up until the modern quantitatively theory of money, which is based on understanding money as a stock that is independent of demand ${ }^{11}$.

good one gets rid of and the good that one acquires. For this distinction, see Von Mises, 2007, p. 4 et seq.

7 Sawyer, in Rochon-Rossi (eds.), 2003, p. 4, distinguishes between "store of wealth" and the classic "store of value". The classic "store of value" is practically synonymous with the establishment of commodity money or what is the same thing, the acceptance (in a short period of time) that if I keep a commodity I do not wish, and the others do the same, it might be used as a commonly accepted medium of exchange. Accordingly, the medium of exchange is based on store value, which is different from the accumulation of this commodity as a "store of wealth". This difference will be important later on; see XX (full text).

${ }^{8}$ Quite often, the ontological concept of "thing" is replaced by other expressions that designate this specific character in the technical language of some science; similar or equivalent expressions, such as "everything that...", or technical concepts such as "assets" or "property", etc. In any case, there is a reference to the concept of "something", the concept of "entity", and this is commonly expressed in these definitions under the formula "anything".

${ }^{9}$ Ingham, 2004, p. 28; Smithin, 2000, p. 3; Fontana \& Vera, in Rochon (ed.), 2003, p. 59; Wray, in Smithin, 2000, p. 42.

10 Schumpeter, 1995, p. 100.

${ }^{11}$ That is to say, in understanding money as an exogenous variable of economic systems; see Bailly and Gnos, in Piégay-Rochon, 2006, p. 220. This is obviously a simplification, a historical "cliché", about which 
But if we have a closer look at the definition, the association between the set of conditions (2)-(4) and (1) is by no means a necessary association. The fact that money has to be "something" (condition 1) does not necessarily mean that money has to be something belonging to the region "physical thing" (condition 2). It does not mean, either, that out of the four functions, the primary function that has to bear this "something" must be the "medium of exchange" function (condition 3). This set of associations have been carried out naturally by both classical and neoclassical economists and popular thought that have always started the genesis of money from the idealized imaginary construct of barter. In the idealized imaginary construct of barter, the medium of exchange function and the constitution of a commodity (a "physical thing") that plays the role of money appear as necessarily related ${ }^{12}$. In contrast, the rest of the functions seem to be able to be carried out more effectively by other entities that do not have to necessarily belong to the region "physical thing" at first sight: in principle, it seems quite intuitive to accept that the function "unity of account" can be better carried out by means of abstract entities than by means of physical things ${ }^{13}$; regarding the function of "means of payment", a payment is a cancelation of an obligation, and therefore it is constituted upon a speech act, whereupon physical money is nothing else than a constitutive possible but not necessary element; and regarding the function of store of wealth, a deposit is an entity that exists independently of the physical existence of the money that constitutes it, as long as it is a pure representation of money ${ }^{14}$.

The comprehension of the functional definition of the orthodox analysis seems to follow the foundational sequence (3) $\rightarrow(2)-(1) \rightarrow(4)$. This is crucial because it involves that the understanding that money has to be "something" is read in light of the constitution of the function of medium of exchange. It is the constitution of the medium of exchange function that will guide the

much more should be said, but it can be considered as a common element of all the special features of this scholar construct an exogenous concept of money, which leads to the axiom of the neutrality of money.

${ }^{12}$ The classic presentation of the theory of the genesis of money as commodity money and the medium of exchange function would be the one by Menger (see Ingham, in Smithin, 2000, p. 17 et seq.); but in Aristotle's analysis in Politics the basic conditions of the narrative are already fixed: money is constituted by the need of exchange, in order to speed the process and make it easier. This is the genesis of money that will give rise to the famous metaphor of money as a "lubricant" of exchanges, the source of all exogenous concepts of money and all theories of money as a commodity.

${ }_{13}$ The circuit theorist Bernard Schmitt pointed out that money "is itself constituted by pure numbers, not at all a commodity, gold or silver... cash, rightly understood, is nothing but money in purely arithmetical variable quality; see Schmitt, in Piégay-Rochon, 2006, p. 186.

${ }^{14}$ See B. Smith, in Koepsell \& Moss, 2003, p. 287 et seq. 
way in which to understand what is meant by the ontological concept of "thing" within the framework of the definition of money. The story of the constitution of the function of medium of exchange that the orthodox analysis carries out consists in the idealized imaginary construction of barter ${ }^{15}$. The most important aspect of the imaginary construction of barter consists in that, as an idealized situation that constitutes the background of money, it prefigures an absolutely pure and spontaneous exchange, "empty" of institutional co-constitutive elements; that is to say, under the imaginary construct of barter lies the historical and logic "garden of Eden" of free market unregulated by state institutions ${ }^{16}$; money that spontaneously emerges from the free exchange of goods ${ }^{17}$. Obviously, the background in the constitution of this imaginary construct is not ontological; it is political. This political background prefigures an idealized world of pure and spontaneous exchanges empty of any legislation. The most proper being of human beings in this construct is the exchange, and the exchange is exchange of goods. The economic concept of "good" is the economic transcript of the ontological concept of "thing", because "good" means "anything that can satisfy a need". The "materializing" dimension of the concept of "good" as economical version of the ontological concept of "thing" is so significant that its use is applied by Menger to the very definition of money: we will consider money "any good" that takes over the three classic functions (medium of exchange, measure of value and store of value, using Menger's terminology). The consideration of money as a good leads Menger so far as to specify the precise empirical conditions that favor the election of a specific thing as money in relation to other things: durability, portability, divisibility, etc. are physical conditions that affect the greater liquidity (Absatzfähigkeit) of a thing and, therefore, facilitate its choice as money.

Therefore, the orthodox understanding of the functional definition starts from the constitution of the function of medium of change in an imaginary construction of politically motivated barter (3); the constitution of this function in-

\footnotetext{
15 The term "idealized imaginary construction" is no stranger to the characteristic methodological terminology typical of the stories of orthodox analysis. Von Mises speaks of the method of imaginary constructions as the "most typical" of economy; see Von Mises, 2007, p. 288.

${ }^{16}$ The "fable of barter", an expression by Servet (2001, p. 16 et seq.) or the "Mengerian myth", an expression by Ingham (in Smithin, 2000, p. 24).

${ }_{17}$ How else would it be possible to obliterate the continuing emphasis of Menger in denying whatever trace of a contractual constitution of money? (Menger, 1997, page 325); "Money is not the result of a previous agreement of economic agents, and even less the result of legislative acts. It is neither an invention of peoples" (ibid., p. 327). See especially the long historical footnote on p. 323.
} 
dicates the background upon which to understand the concept of "thing" (1), and this concept of "thing" is constituted as a "physical thing" ("good", "commodity") (2).

It is important to point out that this association between aspect (1) and all aspects (2)-(4) of the functional definition of money has been a constant in the thematization of the ontology of money, at least up until the publication of Treatise on money by Keynes in $1930^{18}$. By privileging the function of "unity of account" as a primary genetic function regarding the function of "medium of exchange", Keynes opened up an absolutely new field for the treatment of the ontology of money, making it possible to break the association of aspects (2)(3) of the functional definition. If the primary genetic function, from which all others derive, consists in the function of unity of account, then we put ourselves in the genetic context, in this case historical, of the institutional creation of money ${ }^{19}$. The recognition of the origin of money in account money grants a central role to the institution that computes money; to the institution that sets the first equivalences, which are performatively created by law ${ }^{20}$. Something similar occurs if we consider the function of means of payment as primary genetic function: a payment, as a cancellation of an obligation, is in principle independent of whether this cancellation is carried out by means of an abstract quantification $^{21}$. A payment is a constitutive element of a successful speech act, and therefore has its origin in a constituent context of speech acts (promises, obligations, debts, etc.), not in an exchange of goods. Obviously, both a com-

\footnotetext{
${ }^{18}$ Keynes, 1971 , p. 3. Clearly, the Treaty of Keynes did not fall from heaven. The conception of Keynes was very much influenced, especially, by the state theory of money of Knapp (Die Staatliche Theorie des Geldes, 1905).

${ }^{19}$ With regard to methodology, we are at the other end of the method of imaginary constructions. The most important record for us is the historical register in the field of historical data. This "historical trend" was already in Keynes, who talked about "Babylonian madness" to refer to the period of six years during which, in the decade of the 20s (the Treatise dates back to 1930), he devoted himself to the study of metrology and numismatics, and then it is mentioned by some post-Keynesian authors (Wray, 2003; Ingham, 2005).

20 An example of this creation would be the model of the legal constitution of the silver shekel in BabyIon, which would not emerge from a commodity already in circulation, but as the basic unit of account established by the sovereign through law, from which equivalences are established: 1 shekel of silver (equivalent to approximately $8 \mathrm{~g}$ of silver) $=240$ grains of barley.

${ }^{21}$ The question about what comes first regarding medium of exchange and unit of account is more complex than it seems: if there is no quantification we cannot talk about "payment" in the strict sense (see Polanyi, 1994, p. 186), but the recognition that there may be a cancellation of the obligation without quantification seems to place "means of payment" as the scope of the genesis of the unit of account. The problem is the ambiguity of the word "payment": Polanyi restricts it to the use of money, but recognizes that in a broader sense, it is possible to cancel an obligation through actions such as courtship, marriage, dancing, singing, dressing, celebrating, mourn lacerations and even suicide. In these cases there is cancelation of obligations owed to society, but no quantification. It is the context of the complexity of the cancellation of obligations what leads to the formation of the unit of account as a legal means of cancellation of obligations.
} 
modity as an arithmetic variable and a speech act are "something", that is, they can be, at any given time, the "thing" of the aspect (1) of the functional definition, based on the theory of the genesis of the functions we choose.

In this paper, we propose to carry out a phenomenological critique to the idealization processes by means of which the orthodox analysis (which starts all the functions of money from the medium of exchange function) intends to base its whole conception of money. What we want to reveal is how the price paid to demonstrate the possibility of the emergence of a medium of exchange in properly modeled worlds consists in losing, perhaps irreversibly, the possibility of implementing this "artificial" medium of exchange in the life-world.

In order to develop this phenomenological critique we draw on the flagship model for the orthodox analysis in the last 20 years. We refer to the KiyotakiWright model on the emergence of the medium of exchange. We proceed first to a brief exposition of its most important elements, so as to carry out a methodological critique based on the restrictions that a foundation on the life-world would impose on the modeling of worlds, if we were not to miss the more fundamental conditions of meaning.

1. The Kiyotaki-Wright model as a model of emergence of the means of exchange.

The Kiyotaki-Wright model (from now on, KW) is built, from the usual conditions in this type of theoretical entities, starting from the following set of elements:

1. Three distinguishable types of goods, indicated by Arabic numerals, 1, 2 and 3. All goods are stored at a certain cost, but each agent can store only one good at every turn, since the goods are indivisible. The storage costs must be specified according to the good (according to its intrinsic properties) and according to the type of agent (according to the technology used for storage $)^{22}$. With the expression cij we refer to the cost of storage of good $j$ for the type $i$. It is assumed that the costs of storage of goods are structured in the following way: ci3 $>$ ci2 $>$ ci1 $>0$, for all $i$.

\footnotetext{
22 More advanced versions of the model surpass the specification of the cost of storage according to the type of agent, being limited to the proper specifications of the type of good; see Elendner, 2009, p. 31.
} 
2. Three types of agents, whose lifespan is infinite, indicated by means of Roman numbers I, II and $\mathrm{III}^{23}$. When we refer to a token agent (of whatever type) or to a token of one of the three types we denote it with the lower case letter $i$. The agents do not obtain utility for the consumption of the good that they produce, and they do not produce those goods that they wish to consume. ${ }^{24}$

3. For a given agent $i$, the expression Ui refers to the instantaneous utility that results from consumption of the good i. The expression Di denotes the resulting instantaneous desutility of producing the good $i^{*}$. The net utility of consuming and replacing a well suited unit for a produced good is expressed as $u i=U i-D i$.

4. The initial movement in the model can be introduced by means of two possible specifications, which correspond to the combinatory between consumption and production according to the type of agents and the intrinsic proprieties of the goods. In model A the agents of type I produce the good 2 , the agents of type II produce the good 3 and the agents of type III produce the good 1 . In model $B$, the agents of type I produce the good 3 , the agents of type II produce the good 1 and the agents of type III produce the good 2. If we express the two possible combinations between the distribution of the types of agents-goods and the intrinsic proprieties of goods by means of a table, we obtain the following:

\begin{tabular}{|c|c|c|c|}
\hline Agent & $\begin{array}{c}\text { Consumes } \\
\text { (models A } \\
\text { and B) }\end{array}$ & $\begin{array}{c}\text { Produces } \\
\text { (model A) }\end{array}$ & $\begin{array}{c}\text { Produces } \\
\text { (model B) }\end{array}$ \\
\hline Type I & 1 & 2 & 3 \\
\hline Type II & 2 & 3 & 1 \\
\hline Type III & 3 & 1 & 2 \\
\hline
\end{tabular}

\footnotetext{
${ }^{23}$ We will closely deal with the a priori surprising incorporation of the immortality of the agents as a condition for the coherent development of the model.

${ }^{24}$ The probability of obtaining an agent of a particular selected type at random is uniformly distributed," since the proportion of agents per type is the same; see KW, 1989, p. 930.
} 
5. Agents find themselves at each turn randomly in pairs, and must decide whether they will carry out the exchange or not. The exchange always involves a trade-off one by one, among the inventories of the agents, and only occurs if both agree. There is, therefore, no centralized market, and no common space in which goods of the three types are found simultaneously. There is no credit either, since the probability of a pair of agents to meet again is cero ${ }^{25}$. Since time is discreet, it is structured in turns ${ }^{26}$. In a turn, an agent can produce the good that corresponds to him and consume (if he has it) its corresponding good of consumption. Otherwise, he ought to store the good at the corresponding price. In this way, each agent can store only one good at every turn: if he does not consume it, he will have to wait for his turn without producing a new one.

6. Agents follow a set of rational strategies based on the desire to maximize their expected utility. These strategies can be represented by a set of binary variables: $\tau i(j, k)=1$ expresses that the strategy $\tau$ of agent $i$ consists in exchanging the good $j$, which he has in his inventory, for the good $k$, which is in the inventory of the agent with whom he came across; $i(j, k)=0$ indicates that the agent $i$ does not want to carry out the exchange. If we express this from the couple of agents:

$$
\tau i(j, k) \cdot \tau h(k, j)=1 \text {, }
$$

it indicates that the exchange is carried out, where $i$ and $h$ are agents and the first and the second letter in parenthesis designate the good of one's own inventory and the other's own inventory, respectively.

7. Given these elements, it would be possible to determine the probability that an agent who has adopted, on a previous turn, a strategy $\tau i(j, k)=1$, found himself with another agent that allows him to carry out an exchange. To calculate this probability we need to know the proportion $p$ of agents $i$ in possession of the good $j$ in their inventory at time $t$; that is to say, $\operatorname{pij}(t)$. The probabilities of transition from one encounter to another depend on the

\footnotetext{
${ }^{25} \mathrm{KW}, 1989$, p. 931.

${ }^{26}$ Time is not a discrete variable in the life-world. Between two observable values (two seconds, for example) there can always be at least potentially a potential non-observable value. Being constituted upon a model of meetings, the $\mathrm{KW}$ model requires a structure in turns, and therefore time must be represented as a discreet variable, eliminating all intermediate lapses between turns, that then become non-meaningful for the explanatory needs of the model.
} 
conditions of $\operatorname{pij}(t)$ on a given time; therefore, $\boldsymbol{p}(t)=(\operatorname{pij}(t))$, where $\mathbf{p}$ signals the matrix of the transition of probabilities ${ }^{27}$.

8. From this description of the surroundings and the rationality of the agents, the model provides the definition of what is meant by "equilibrium". The conception of equilibrium that underlies the $\mathrm{KW}$ model is a Nash equilibri$\mathrm{um}^{28}$ :

"A stationary equilibrium of Nash is a set of strategies of exchange $\{\tau l\}$, one for each type $i$, with a stationary distribution of inventories $\mathbf{p}$, satisfying:

a. Maximization: every token $i$ chooses to maximize its expected utility given the strategies of others and distribution $\mathbf{p}$;

b. Rational expectations: given $\{\tau l\}, \mathbf{p}$ is a resulting stationary distribution". 29

The $\mathrm{KW}$ model pretends to find situations of equilibrium from these surrounding and behavioral conditions of the agents. According to this, the matrix of the exchanges in the first encounter can be traced as follows:

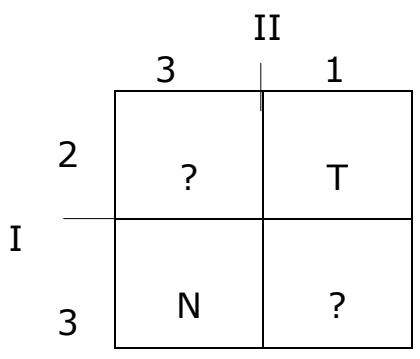

I finds II

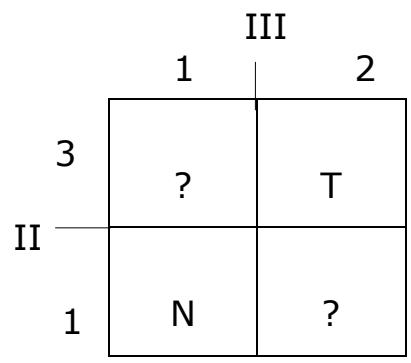

II finds III

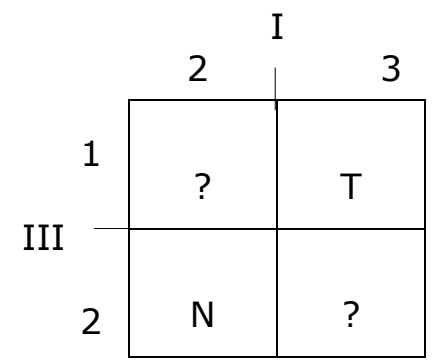

III finds I

where letter $\mathrm{T}$ signals that there will be an exchange, and letter $\mathrm{N}$ signals that there will be no exchange. In the first case (an encounter between a type I agent and a type II agent), the rows indicate the possibility that I possesses good 2 or good 3, and the columns signal the possibility that II possesses good

\footnotetext{
27 The transition matrix indicates the probability that the next possible state of the stochastic process is one determined in accordance with the determination of the present state. The mathematical basis of the KW model basically consists in methods of dynamic programming and optimal control; in this case Markov chains are applied.

${ }^{28}$ In his general definition, a Nash equilibrium is one in which each player (a) knows and has adopted the best strategy; (b) knows the strategies of others. Therefore, all players put into practice (and know they do) the strategy that maximizes his profits given the strategies of others. Therefore, no player has incentives to individually modify his strategy. Nash equilibrium is not the best overall result for all participants; it is just the best outcome for each of them, individually.

${ }^{29} \mathrm{KW}, 1989$, p. 932.
} 
3 or 1 . If agent I possesses good 2 and agent II possesses good 1, then there is a double coincidence of wants, and the exchange will always occur. We recall the condition of the exchange:

$$
\tau i(j, k) \cdot \tau(k, j)=1
$$

and if we specify it in the present situation, we can write:

$$
\tau I(2,1) \cdot \tau I I(1,2)=1
$$

Let us recall that agents of type I consume 1, agents of type II consume 2 and agents of type III consume 3.

Let us look instead to what happens if agent I possesses good 3 and agent II good 3 (or, simply, in all cases in which the two agents at the meeting possess the same type of good). In these cases, the exchange will never occur; indeed:

$$
\tau I(3,3) \cdot \tau I I(3,3)=0 \text {. }
$$

What happens in the other cases; that is to say, in the cases in which the agent I possesses good 2 and agent II possesses good 3, on the one hand, and the case in which the agent I possesses good 3 and agent II possesses good 1 ?

$$
\begin{aligned}
& \tau I(2,3) \cdot \tau I I(3,2)=? \\
& \tau I(3,1) \cdot \tau I I(1,3)=?
\end{aligned}
$$

In these cases, the exchange can occur or not, depending on the strategy chosen by the agents. If we consider that agents will always prefer to trade with goods that have a lower cost of storage, and recall that we provided storage costs as follows: ci3 > ci2 > ci1 > 0, we can conclude that if agent I possesses a good 2 he will not trade it for a good 3, which implies a higher cost of storage. The same can be said of the agent II when he possesses a good 1, which has storage costs than 3. Therefore:

$$
\begin{aligned}
& \tau I(2,3) \cdot \tau I I(3,2)=0 \\
& \tau I(3,1) \cdot \tau I I(1,3)=0
\end{aligned}
$$

Incorporating logical storage costs to decision-making strategies, we have the complete matrix of the first exchanges in model $A$ : 


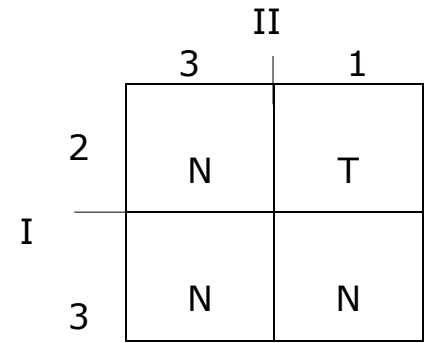

I finds II

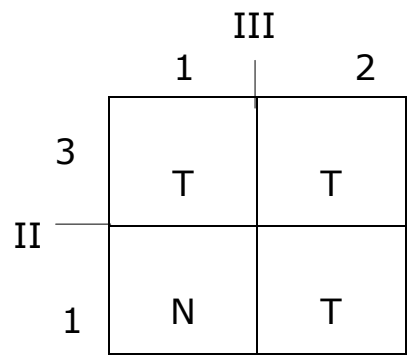

II finds III

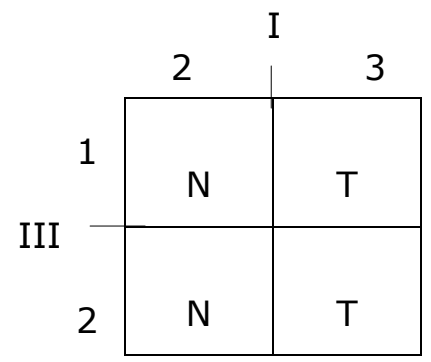

III finds I

Let us take for instance the matrix of the encounters between the agent type II and agent type III. In this case, if agent II possesses good 3, he will want to exchange it for good 1, since the former implies a lower storage cost. But agent III will also want to exchange it, since good 3 is the good he consumes. Therefore, the exchange will occur:

$$
\tau I I(3,1) \cdot \tau I I I(1,3)=1
$$

The matrix of this entire array of encounterings can in turn be represented by the following scheme, which displays the fundamental equilibrium:

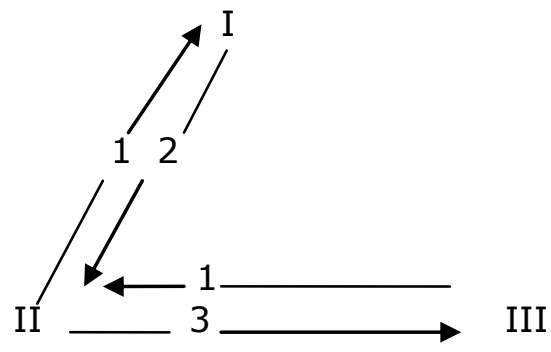

Let us notice that type II agents end up acting as intermediaries accepting good 1 from agents of type III to exchange it for good 2 of agents of type I. This implies that good 1 is the good that emerges as a means of exchange from the behavior of agents of type II. This equilibrium is considered fundamental because the strategies from which it is obtained are "fundamental": that is, the agents consider only the criterion of cost of storage (remember: ci3 > ci2 > ci1 $>0$ ) with the exception of a situation in which the greater cost of storage is its own consumer good. The model KW deals in a differentiated fashion with an- 
other kind of equilibrium, speculative equilibrium, based on speculative strategies. One strategy is speculative when, besides the above-mentioned "fundamental" criteria (storage costs and consumer good), the criterion of the probability of getting rid of an unwanted good in a smaller number of turns is added in spite of the fact that conserving it meant a greater storage cost. If we incorporate speculative strategies in addition to fundamental strategies, we obtain the speculative balance of model $A$, represented in the following scheme:

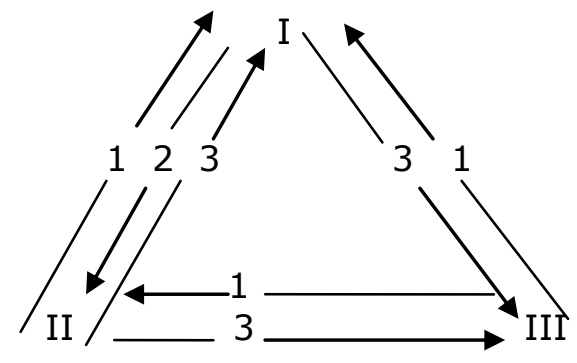

, in which we can see how two goods that carry out the function of medium of exchange emerge: the goods of type 1 (that already emerged in the fundamental equilibrium, because agent II continued transferring good 1 from agent III to agent I), and the goods of type 3 (since now, incorporating speculative strategies, the agents of type I transfer good 3 from agent II to agent III). In this new equilibrium, agents of type I prefer the good of greater cost of storage (3) in relation to the lower-cost good (2) precisely because good 3 is easier to market; that is to say, it can be exchanged more easily if we bear in mind the probabilistic factor of encounterings.

After a considerable number of turns, the following conclusion should follow:

- The good of type 1 , in having less storage costs, should emerge as a medium of exchange.

- The agents of type II are at a disadvantage because they produce the good 3 (the most expensive from the point of view of storage), which will only be accepted by agents of type III (who consume it directly). This is what will take them to use good 1 (produced by III) as a medium of exchange with the agents of type I.

- Some agents of type I might decide (if they adopt some speculative strategy) to store good 3 (with a greater cost of storage) in view of being able 
to directly carry out an exchange with agents of type III, without the need to go through the mediation of agents of type II. This would mean a speculative equilibrium whereby good 3 would also occasionally emerge as a medium of exchange.

3. Phenomenological critique to the Kiyotaki-Wright model. Notes for a theory of money in the life-world.

Theoretical economists that work using models are quite aware of the limitations in scope that their methodology implies. What the model $\mathrm{KW}$ shows is that the emergence of a medium of exchange in an appropriately modeled situation is possible; that is to say, given an initial state of the stochastic process without the existence of any medium of exchange, the process will move towards the emergence of at least one good that will play the role of medium of exchange. But it is necessary to reflect upon the way in which Kiyotaki and Wright have constructed their model; that is to say, about what factors it has been necessary to isolate in order to show the possibility of that emergence. With this, we intend to ponder about a capital methodological question: if the price paid in the way of the process of the isolation of factors and of idealization in the constitution of the modeled elements does not imply the loss of essential elements when it comes to understand the sense of the emergence of money. It is one thing to show that under certain conditions (although these conditions can never be given in the real world) the emergence of a medium of exchange would be possible; another is to understand the sense that the emergence of a medium of exchange has in general. Demonstrating that in a possible properly modeled world the emergence of a medium of exchange can be given through stochastic processes does not imply an advance when having to understand the meaning that the emergence of money might have in the real world. If some of the isolated factors in the constitution of initial elements was revealed as decisive when having to understand the meaning of the emergence of money, maybe what is gained (the possibility of demonstrating the possibility of the emergence of money in a possible world) might seem a much less attractive reward than we would have first imagined at a theoretical level. 
The architecture of the model Kiyotaki-Wright corresponds quite precisely with a type of theoretical entities that started to develop in the field of economy in the 70s. Although the concept of "model" was already frequently used in economy in the 20s with a generic and approximately equivalent meaning to the one of "theoretical construct", starting from the 70s the word "model" came to mean a more specific and characteristic type of theory. ${ }^{30}$ First, these new models focus on the analysis of very specific issues, moving away from the will to generalize, which previous theoretical constructions that were also formalizing had, such as the Theory of General Equilibrium. ${ }^{31}$ In this sense, the model $\mathrm{KW}$ starts from the assumption that the distinctive trait of money is the medium of exchange function, and any other function is immediately eliminated from the analysis. It could also be said that there is no theory of money in the model KW, but an "isolated" theory of the function of medium of exchange; and not of its meaning, but only of the confirmation of its apparition. On the other hand, the modeling of the initial conditions is carried out by means of informal language. In the model $\mathrm{KW}$ (and in the models in the new specific sense after the 70s) the formal model is integrated in a "history" that is presented by means of an informal language ${ }^{32}$. This story presupposes the description, in non-formal language, of modeling (by means of idealizing and isolating processes) of three broad areas, almost always present in the constitution of such theoretical entities:

1. The environment: The modeling of the environment is usually carried out by means of isolation and idealization processes. In the case of the model KW that concerns us here, the environment is specified as physical environment, so as to distinguish it from the modeling of behavioral aspects" ${ }^{\prime 33}$. However, in the

\footnotetext{
${ }^{30}$ On the distinctions between the generic use and the more technical concept of "model" in economics from the 70s, see Garcia-Bermejo, 2009, p. 90 et seq. While the word "model" was already frequently used, the new meaning derives rather from its verbal sense, "to model", in the construction of entities designed to capture specific aspects of the market.

${ }^{31}$ Although there is no theory of money, in the strict sense, within the theory of General Balance, it can be argued that is a theory that tends to generalize and potential treatment of multiple issues.

32 "Story" is the word that, not without derogatory overtones, tends to qualify the abundant description in informal language around the entire formalized exhibition of the model; see García-Bermejo, 2009, p 96. Contrast, again (as does García-Bermejo) with a much more rigid conception of formalization of the theory of general balance, and with the methodological observation of Debreu about the complete dominance of the syntactic over the semantic level in the theory: "Fidelity to rigor dictates the axiomatic form of the analysis where the theory, strictly speaking, is logically disconnected from its interpretations (see Debreu, 1973, p. x).

${ }^{33} \mathrm{KW}, 1989$, pp. 930 - 931. Since there is no single pattern in the development of models, the word environment often includes both the physical description of the medium and the description of the modeled behavior, without making any explicit difference; see García-Bermejo, 2009, p. 92.
} 
description of the environment of the model $\mathrm{KW}$ we can distinguish some heterogeneity:

a. On the one hand, space-time idealizations of the physical world, of the same type that would take place in the natural sciences. Thus, time is considered a discrete variable (when it is not in the life-world), and the spatial limitations of storage are fixed as an assumption ${ }^{34}$. In a certain sense, these idealizations are made to facilitate a simpler mathematical expression of the fundamental operations of the model. This sense of "idealization" is paralleled to the "neo-Duhemian" sense of idealization according to which idealization is a method of transforming raw data; that is to say, a method of correcting systematic errors generated by devices of factual measurement ${ }^{35}$. Husserl also reflects this sense of "idealization" when he affirms that "the art of measurement becomes the precursor of at last universal geometry and its "world" of pure limit-forms" ${ }^{\prime 36}$. Nothing points to a problematization of this type of idealization, similar to the one physics carries out in the bodies that are given to it in sensible perception.

b. On the other hand, the description of the characteristics of the agents also shapes the environment. And this description is not without interesting details. Why do agents have to be immortal? The model does not say anything in this respect. Obviously, the introduction of the immortality of the agents in the constitution of the model (because it practically figures more as an introduction than as an isolation, since even if we all know in some way that we will die, we consider this aspect negligible in $99 \%$ of our daily commercial exchanges) ${ }^{37}$ can be explained, as in the previous case, in virtue of a simplification in the application of the mathematical apparatus to be used, since if we introduce the immortality of agents we can avoid distortions in the establishment of the calculus of the

\footnotetext{
${ }^{34} \mathrm{KW}, 1989$, p. 930.

${ }^{35}$ About this neo-Duhemian sense of idealization, see Sebastián, in García-Bermejo, 2009, p. 401.

${ }^{36}$ See Hua VI, § [9], (a), p. 25: "MeBkunst wird also zu Wegbereiterin der SchilieBlich universellen Geometrie und ihrer "Welt" reiner Limesgestalten".

37 There are millions of negligible aspects in the modeling of exchange that have not been "explicitly" isolated in the "story" of Kiyotaki and Wright, for example, whether the agents are handsome or ugly, that they do not suffer a disability of any kind, etc. In contrast, the fact of death makes an explicit reference to its isolation. If we asked ourselves about what factor plays a greater role in a commercial exchange in the life-world, whether the beauty of the agents or their mortality and, therefore, what is the factor that can be the best isolated in the idealization, surely we would find more than a theoretical problem. However, KW chose to make the elimination of death explicit and not to say anything about the isolation of other special characteristics of the agents. Therefore, we can assume that this explicitness obeys some kind of logic, whatever the extent to which this logic is not made explicit.
} 
functions of utility and non-utility of the agents, on the one hand; and on the other, we stabilize the number of agents of each type I, II and III, and in this way the calculus of probability of encounters is also stabilized. However, if these were the only reasons, we would have to also include a clause on the birth of the agents (the model does not make this clause explicit), since this factor could also alter the factor of probability of the encounterings. The model KW talks about the "continuum" of agents as a "unity of mass", implying a single fixed number and compact and stable whole of agents. However, the immortality and absence of birth of the agents in the model ${ }^{38}$ is not the only modeling characteristic of the agents. The agents "meet each other". This is the only relation between them. Production is understood as an absolutely individual factor, and the agents interact with each other having related meanings in which they exchange goods. This is a priori reasonable under the logic of the constitution of models: we want to show the emergence of the medium of exchange, and other related structures between the agents can and must be negligible. At the same time, one can interpret that the essential nucleus of the commercial exchange consists in the type of exchange we call "meeting", and we can assume that all possible relations but "meeting" can be isolated. But in this case, the modeling structure of these encounters (its rhythmic pace organized into discreet time turns) implies that the probability that two agents meet again is zero ${ }^{39}$. No doubt, our extreme precautions would not be properly understood if it was understood that our aim is to denounce some "lack of empathy" or some other inappropriate isolation in virtue of the exclusion of, for example, emotional factors or social ties in meetings. Staying in a modeling that isolates all emotional or family ties between the agents, and accepting it as methodologically reasonable, what should concern us is the explanation according to which the probability for two agents to meet again is zero: the elimination of the

\footnotetext{
${ }^{38}$ Although birth is not made explicit as a modelized element, we have to assume that the same perspective must be assumed starting with the introduction of the sense of immortality. Or perhaps Kiyotaki and Wright have assumed that a world of immortal agents is a world in which no one would like to have children, and therefore one condition follows another in an immediate and obvious way? On the other hand, one might think that dying can be included as a complete cessation of "economizing actions", the only ones in which the model is centered, while procreation can be immediately eliminated from "economizing actions". Everything is open to interpretation, given that KW do not say anything about it; in any case, these issues would require some explicit demonstration in the development of the model.

${ }^{39}$ KW 1989, p. 931.
} 
credit in the model. It is necessary to stress that we are not calling for the "humanity" of agents; that would be ignoring the precise meaning of what the concept of "model" ontologically means, nor the intentions of the researchers who use those theoretical entities, attacking the processes of isolation and idealization by means of a critique aimed at adding convolutions (sociological, psychological, institutional) on the aspects the scientist tries to isolate according to his theoretical interests. However, the denial of the possibility of credit in the model is not the isolation of a concrete social relation between agents among other possible social relations; it does not involve the isolation of an accidental relation to the phenomenon of money itself, which we want to explain. We are talking about a relation that all other monetarist traditions confound with the essence itself of the phenomenon of money. Actually, to eliminate credit from the concept of money in the model $\mathrm{KW}$ means that the probability of two agents who meet in a turn to meet again is zero. One could ponder whether what has been isolated in this logic of meetings is the notion of "society" itself. And to isolate, not this or that determined social factual relation (being part of a family, having emotional bonds, etc.), but the notion of "society" itself is possible that it implies to gain the description of the emergence of the medium of exchange in a possible world under the condition of not being able to obtain a theory in which the emergence of the medium of exchange, as well as its ties with the worldly concept of money become intelligible for individuals who belong to the real world (the "life-world", as we would say phenomenologically). In order to eliminate the possibility of credit in the model (to "isolate" the function of medium of exchange from other functions), we eliminate the notion of "society" itself: two agents that meet in a turn have a zero probability of meeting again. With this, we might legitimately ponder about the possibility of recovering, some time, some empirical content from the model (or for the possibility of recovering the emergence of the medium of exchange for the life-world). We emphasize that our criticism is not far from the same thematic area of money; the model $\mathrm{KW}$ requires from the beginning to forget any bond that the emerging medium of exchange could have with a "social" time. Even if it emerges from a series of stochastic processes, this medium of exchange is purely spatial; it does not have a temporal dimension. We could ponder 
whether a medium of exchange obtained at this price has something to do with the function of "medium of exchange" as we exert it daily in the lifeworld; that is to say, we could ponder whether this medium of exchange has anything to do with the function of medium of exchange as it corresponds to the phenomenon of money as it is experienced. And this is not precisely a "personalist" critique to economy ${ }^{40}$.

2. Behavior: The model KW presents human behavior modeling according to two parameters: the theory of rational election and the theory of games. With regard to the rational to the theory of rational election, the agents are considered as rational maximizes: always and at all times every agent seeks to maximize its expected utility, and this maximization guides unilaterally his decision making. The theory of rational election is based upon the microeconomic formalization of a previously modeled behavior. These microeconomic formalizations, at their turn founded upon a previous idealization of behavior, are carried out isolating some components of the decision making psychological and social process. But regarding this microeconomic formalization, based in its turn in the idealization of certain psychological aspects of decision making, we could ponder: Is it legitimate to model the psychic processes of decision making in the same way that the natural sciences model the space-time phenomena with which they must operate? Can we talk about concepts such as ideal perfect fluid or gas, habitually used in physics, and say that there is some analog relationship with concepts such as those defined by consumer preferences and income, or governments uniquely represented by fiscal or monetary variables? ${ }^{41}$ From the purely formal point of view, we give a positive answer: there is no pure fluid in nature, although the theoretic study of the properties of a perfect fluid can lead to laws that applied to real fluids, can help us explain or predict quite approximately the experimental results; likewise, it will be said, in reality consumers are not defined solely by their preferences and income, but to assume a human action of this kind should allow us to explain or predict some

\footnotetext{
${ }^{40}$ In a sense, the KW model evolution in the last 20 years confirms the "artificial" character of this medium of exchange: instead of evolving toward an incorporation of institutional or closer to the real world elements (working in an interdisciplinary direction to reconcile the more formal aspects of the model by introducing concepts from other social sciences), the model has evolved into theoretical proposals that attempt to broaden its field of action in completely created computer simulations, or what has been called "artificial societies"; that is to say, instead of advancing in the direction of modeling the formal nucleus of the model, progress has been made in the direction of "modeling" all the surrounding aspects, including the notion of society; see Elendner, 2009.

${ }_{41}$ This analogy can be found in Santos, in García-Bermejo, 2009, p. 242.
} 
accurate experimental results. But, is it really the case in the example we are analyzing of the model $\mathrm{KW}$ about the emergence of money ${ }^{42}$ Are the results of the $\mathrm{KW}$ model recoverable to establish or construct some explanation or prediction in the real world? If the constitution of a perfect fluid by means of idealizing processes allows for laws applicable to the explanation of predictive behavior of real fluids, it is because the idealization of a perfect fluid is carried out isolating factors that belong to the same ontological regional level. The viscosity, rotational character or compressibility of a liquid are factors that can be isolated in the idealization of a perfect fluid, but a perfect fluid is nothing else than a real "polished" liquid from the worldly conditions that impose restrictions of measurement and prediction. In a sense, in the example of fluid mechanics we still move in the direction of the neo-Duhemian sense of "idealization", previously discussed. However, when we model human decision making in the constitution of these economic models, do what is obtained and what is isolated still belong to the same ontological regional level? Is the relationship between a medium of exchange obtained by emergence from some immortal, sterile agents that can never be found more than once, and a medium of exchange, for example an act of buying, such as the one we might find in its constitutive spatial levels in the life-world, a relationship between two theoretical entities that belong to the same regional and ontological level? Hastily assuming a positive answer implies once again to forget that the model $\mathrm{KW}$ is not a model about the emergence of money, but about the emergence of the function of the medium of exchange, and that if the demonstration of this function can be carried out, it is at the price of having previously isolated it from other functions of money, from which the model simply does not affirm anything. Regarding the question of whether the modeling behavior and the behavior obtained by means of the recourse to phenomenological description of the life-world belong to the same regional and ontological level, we call upon Husserl again:

"The idea of an ontology of the world, the idea of an objective, universal science supported by a universal a priori according to which all possible factual world was knowable more geometric - an idea available from Leibniz - is nonsense. In the area of souls (Seelen), in principle, there is no such ontology;

\footnotetext{
${ }^{42}$ We are not criticizing the possibilities of empirical contrast of models in general (in fact, I am far from having accurate information about it); our view is restricted to the $\mathrm{KW}$ model now, as a step towards a global theory of money using the medium of exchange function.
} 
there is no science of the ideal and physicist type, even if psychic being can be studied in transcendental universality and in a systematic way, and in the main essential generality in the form of an a priori science. ${ }^{43}$

3. A condition of equilibrium: The concept of equilibrium implies an assumption in the way in which the agents are going to behave, and this behavior is based here in the theory of games. The notion of equilibrium is introduced as a model resolution clause, and in the model $\mathrm{KW}$ it depends on the distinction between fundamental strategies and speculative strategies. In this case, the whole question of the ontology of modes of being of things has been absorbed in the theory of strategic behavior stipulated by the model.

Concluding: the Kiyotaki - Wright model has managed to show that, if money was a medium of exchange, it could exist in a possible world. Some see this as a breakthrough in the orthodox analysis of money ${ }^{44}$; others, more cautious, limit their view to the confirmation of the possibility of an "old intuition $^{\prime \prime 4}$. Whatever the scope we give to this model, we must point out that we are not in front of an isolated theory of money, but in front of a theory about one of the isolated and modeling functions of money. As we have seen, the model KW leaves the question about the genetic ancestry of these issues in relation to other functions absolutely intact.

\section{BIBLIOGRAPHY}

AIYAGARI, S. Rao \& WALLACE, Neil: Existence of steady-states with positive consumption in the Kiyotaki-Wright model, Research Department Working Paper no 428, Federal Reserve Bank of Minneapolis, 1991 (Disponible en: http://www.greatdepressionbook.com/research/WP/WP428.pdf)

AYDINONAT, N. Emrah: The invisible hand in economics. How economists explain unintended social consequences, New York, Routledge INEM Advances in Economic Methodology, 2008.

DEBREU, Gerard: Teoría del valor. Un análisis axiomático del equilibrio económico, Barcelona, Ed. Bosch, 1973.

ELENDNER, Hermann: On the emergence of money. The formation of media of exchange in artificial societies, Saarbrücken, Verlag Dr. Müller, 2009.

\footnotetext{
${ }^{43}$ Hua VI, § [72], p. 268.

${ }^{44}$ Elendner, 2009, p. 29.

45 Aydinonat, 2008, p. 112.
} 
GARCÍA-BERMEJO, Juan Carlos: Sobre la economía y sus métodos, Madrid, Trotta, 2009.

GONZÁLEZ, Joan: Fenomenología estática de los actos de compra, en COPOERU, Ion \& SEPP, Hans Rainer (eds.), Phenomenology 2005, Vol. III. Selected essays from the euromediterranean area, Bucharest, Zetabooks, 2007.

- "Materiales para una investigación fenomenológica sobre el dinero", Revista Arbor, CSIC, no 736 (2009), pp. 289-302.

- "Ontología y funciones del dinero", Investigaciones Fenomenológicas, vol. monográfico no 3 (2011), "Fenomenología y Política".

HICKS, J.R.: Critical essays in monetary theory, Oxford, Clarendon Press, 1967.

HUSSERL, Edmund: Hua III, Ideen zu einer reinen Phänomenologie und phänomenologischen Philosophie. Erstes Buch, Martinus Nijhoff, 1950.

- Hua V, Ideen II, Martinus Nijhoff, 1952.

- Hua VI, Die Krisis der europaïschen wissenschaften und die transzendentale Phänomenologie, Martinus Nijhoff, 1954.

- Hua XXXIX, Die Lebenswelt. Auslegungen der vorgegebenen Welt und ihrer Konstitution. Texte aus dem Nachlass (1916 - 1937), Springer, 2008.

INGHAM, Geoffrey: The Nature of Money, Cambridge, Polity Press, 2005.

- Capitalismo, Madrid, Alianza, 2010.

KIYOTAKI, Nobuhiro \& WRIGHT, Randall: "On money as medium of exchange", Journal of Political Economy, vol. 97, no 4, Univ. of Chicago Press, 1989.

- "A search-theoretic approach to monetary economics", The American Economic Review, Vol. 83, no 1, 1993 (Disponible en http://www.pse.ens.fr/ragot/KW93.pdf)

MENGER, Carl: Principios de economía política, Madrid, Unión Editorial, 1997.

PIÉGAY, Pierre (Ed.): Teorías monetarias postkeynesianas, Madrid, Akal, 2006.

POLANYI, Karl: El sustento del hombre, Barcelona, Mondadori, 1994.

ROCHON, Louis-Philippe (Ed.): Modern theories of money. The nature and role of money in capitalist economies, Edwar Elgar, Cheltenham, 2003.

SIMMEL, Georg: Philosophie des Geldes, Gesamtausgabe Band 6, Frankfurt a. M., Suhrkamp, 1989.

SERVET, Jean-Michel: "Le troc primitif, un mythe fondateur d'une approche économiste de la monnaie", Revue Numismatique, vol. 6, no 157 (2001)

SMITHIN, John (Ed.): What is money?, Nueva York, Routledge International Studies in Money and Banking, 2000.

VON MISES, Ludwig: Teoría del dinero y del crédito, Madrid, Unión Editorial, 2007.

WRAY, Randall L: Understanding modern money, Cheltenham, Edward Elgar Publishers, 2003.

- (Ed.): Credit and state theories of money. The contributions of A. Mitchell Innes, Cheltenham, Edward Elgar Publishers, 2004. 